\title{
Eduardo J. Couture y la literatura. \\ La Parábola de los cuatro príncipes: la tolerancia y otros valores
}

Eduardo J. Couture and Literature.

The Parable of the Four Princes: tolerance and other values

\author{
María Cecilia Barnech Cuervo \\ Universidad Católica del Uruguay \\ ORCID: 0000-0002-5096-4372 \\ Correo: mbarnech@hotmail.com \\ Recibido: 24/03/2021
}

Aceptado: $28 / 04 / 2021$

\section{Resumen:}

Eduardo J. Couture es considerado como uno de las grandes juristas del S XX y, especialmente, reconocido por sus aportes en el área del derecho procesal. Sin embargo, tal vez no lo sea, en la misma medida, por su obra literaria. En el presente se abordan sus concepciones sobre la justicia, la libertad, el orden y la tolerancia en la Parábola de los cuatro príncipes, desde una mirada más estética, pero, no por ello, menos profunda. Este estudio permite también advertir sobre la relevancia de las posibles relaciones entre Derecho y literatura.

Palabras clave: Derecho; literatura; Couture; parábola; tolerancia.

\begin{abstract}
:
Eduardo J. Couture is considered one of the great jurists of the 20th century and, especially, recognized for his contributions in the area of procedural law. However, it may not be, to the same extent, because of his literary work. In the present his conceptions about justice, freedom, order and tolerance are addressed in the Parable of the Four Princes, from a more aesthetic point of view, but, not for that reason, less profound. This study also allows us to warn about the relevance of the possible relationships between Law and literature.
\end{abstract}

Keywords: Law; literature; Couture; parable; tolerance. 


\section{Introducción}

El filósofo del Derecho que se aventura en las costas de la literatura es una especie de Colón, que al asentar pie en el nuevo mundo ignora la exacta naturaleza de su descubrimiento. ¿Es acaso una isla o un continente? Serán muchos más los descubrimientos que lo estarán esperando y, con toda seguridad, se verá obligado a modificar los mapas que presuntamente ya había delineado (Ost, 2006, p. 348).

La sociedad contemporánea, frágil, "líquida" (Bauman, 2002) y disruptiva (con un ser fragmentado, desconectado de su naturaleza) nos impone, particularmente, repensar el derecho y sus conceptualizaciones actuales dominantes. El estudio de obras literarias que permitan abordar la relación entre Derecho y literatura puede aportar reflexiones para enfrentar esta aporía, desde una mirada interdisciplinaria (Cárcova, 2000). Pueden reconocerse diferentes modalidades de vincularse el Derecho y la literatura, de "tender un puente" entre ambas disciplinas (Marí, 1998, pp. 251-287).

Siguiendo a Ost (2006, pp. 334-335), esta relación puede comprenderse desde tres perspectivas. La denominada "el Derecho de la literatura" refiere principalmente a la protección de la libertad de expresión, la prohibición de la censura, los derechos de autor, es decir, la protección jurídica de la literatura, en sentido amplio, como forma de creación y expresión.

La perspectiva desde "el Derecho como literatura" se encarga del estudio del derecho como discurso, su retórica, su estilo y lenguaje propios, calificado, por Ost, como dogmático, tautológico y performativo.

Por último, la dimensión desde la cual se aborda este trabajo, "el Derecho en la literatura", alude a cómo se asume, en la literatura, cuestiones tales como la justicia, el Derecho o el poder, tan propias del análisis filosófico-jurídico. En este contexto, el arte, en general, nos enfrenta a cuestiones jurídicas y al mismo concepto de justicia, desde una mirada más vivencial.

Por ello, tal vez sea la Filosofía del Derecho, dentro de las áreas jurídicas, la que más ha reparado en esta interacción - o "el fecundo maridaje" entre Derecho y Literatura - permitiendo, como advierte Lorca, una concepción jurídica menos dogmática y formalista, y más centrada en el carácter cultural del Derecho (Lorca, 2012, pp. $119-121)$. 
Este abordaje resulta pertinente, no solo porque se ha ido desarrollando en estos últimos tiempos en Latinoamérica (ya viene de más larga data en Estados Unidos y Europa), sino porque en Uruguay, particularmente, se le ha dado relativamente poca relevancia (Meliante Garcé y Sosa, 2018, p. 60).

El presente trabajo pretende plantear cómo Eduardo J. Couture ${ }^{1}$ concibió, en forma adelantada para su tiempo, esta interrelación entre las disciplinas y además, presentar una de sus obras literarias, la Parábola de los cuatro príncipes, que nos permite disfrutar sus concepciones sobre la justicia, la libertad, el orden y la tolerancia desde una mirada más estética, ficcional pero, no por ello, menos profunda.

\section{¿Cómo Couture funde derecho y literatura?}

¿Quién, al observar el carácter árido, seco y frecuentemente iliterario de nuestros códigos y de nuestras leyes, el apartamiento actual entro las profesiones del poeta y del juez, habría de imaginar ni creer, si, por otra parte, no se lo enseñara la historia, que hubo un tiempo en que el derecho

y la poesía se hallaban estrechamente unidos, se mecían, según la gráfica frase de Grimm, en la misma cuna y vivían, por decirlo así, una misma vida? (Hinojosa, 1904).

Sin dudas, es considerado como uno de las grandes juristas del $\mathrm{S} X \mathrm{XX}$ en Uruguay y su obra, especialmente, desde el área de derecho procesal es valorada en toda Latinoamérica. Sin embargo, merece ser reconocido, también, por su relación con la literatura y su destacada inclinación por la palabra, en general:

Eduardo J. Couture, un hombre libre, un hombre ilustre ilustrado por su propio esfuerzo, un espíritu sensible y delicado y una inteligencia lúcida. [...] De cualquier manera, es, por lo menos, un artífice de la palabra y no creo exagerar en los términos de esta presentación. [...] Creo que cuando vosotros os ausentéis de este local iréis repitiendo conmigo: En mi alma está enarbolada la bandera en que se aloja el sol de la libertad y está mecida o acariciada por una brisa que viene desde el Este, desde la

\footnotetext{
${ }^{1}$ Couture nació en Montevideo el 24 de mayo de 1904 y falleció el 11 de mayo de 1956. En 1927 se graduó de abogado y comienza su carrera docente. Fue director de la revista Derecho, Jurisprudencia y Administración, así como miembro de varios institutos y academias, decano de la facultad de Derecho de la UDELAR, académico de número de la Academia Nacional, Medalla de Oro del Ministerio de Instrucción Pública, comendador de la Ordem Nacional do Cruzeiro do Sul (Brasil) y caballero de la Legión de Honor (Francia).
} 
comarca pequeña entre el mar y el Río de los Pájaros. (Martínez Segovia, 1956, pp. 99-121)

Couture no sólo debe ser visto como un jurista, sino también como un cronista y un escritor literario. Como jurista alcanza con mencionar algunas de sus obras, desde el Vocabulario Jurídico, Fundamentos del Derecho Procesal Civil, Estudios del Derecho Procesal Civil y el Proyecto de Código de Procedimiento Civil (inspirador de códigos procesales de Latinoamérica). Ya como cronista se destaca la obra compiladora de sus crónicas de viaje La Comarca y el mundo. Tampoco pueden soslayarse las cartas que intercambiaba con grandes personalidades de la época. Quienes, como Buonocore, fueron contemporáneos y protagonistas de esos diálogos, las reconocen como un gran aporte al "género epistolar" (Buonocore, 1957, pp. 106-107). Y como escritor literario nos dejó obras breves, que nos ilustran su pensamiento más filosófico, sobre lo que nos detendremos en el apartado siguiente.

Pero también advirtió, tempranamente, la interrelación entre las disciplinas derecho y literatura. En oportunidad de una conferencia magistral en Paraná titulada Tres poetas del Derecho: Bentham, Valery, Rodó, demuestra su admiración por la poesía a través de su semblanza a Paul Valery, poeta que encontró su gloria luego de abandonar los estudios de derecho:

Cuando terminó sus estudios escolares y liceales, pasó a la universidad de Montpellier, donde inició y abandonó sus estudios de derecho. Un día los juristas tendremos que hacer un homenaje a todos los que no terminaron la carrera. Será el más grande homenaje a todos los que no consiguieron ser como nosotros porque llegaron a ser muy superiores a nosotros.

También al recorrer los pasos de estas tres personalidades destaca en este vínculo arte y derecho:

He elegido solamente tres de los escritores que más vivamente han influido sobre mi formación espiritual, dos de cuyos tres no son específicamente juristas en el sentido de la palabra, pero que han tratado a fondo y magistralmente el pensamiento jurídico, para mostrar cómo es posible que tres filósofos un poco intuitivos y otro poco reflexivos del derecho pueden mostrarnos de qué manera un pensamiento jurídico, cuando adquiere dimensión de profundidad, llega a tocar los límites de la 
poesía [...]Quisiera mostrar que la poesía del derecho que ellos pudieron haber enseñado no estaba tanto en su contenido filosófico como en su significado moral, porque, al fin y al cabo, una idea de progreso, una idea de humildad y una idea de tolerancia no son sino profundas manifestaciones de la entraña moral del hombre. Los juristas divagan mucho y hay libros enteros escritos para mostrar la coincidencia o el contraste entre la moral y el derecho (Couture, 1956, pp. 99-121).

En estos fragmentos queda de manifiesto su visión acerca del derecho y la necesidad de vincularse con otras disciplinas, especialmente creativas, que amplíen la formación del jurista.

Reconoció tempranamente al Derecho como cultura. En su discurso de homenaje a Irureta Goyena, compartiendo su pensamiento, ensena:

Irureta entendió el derecho como cultura, porque él tenía particular sentido de la belleza. [...] La proporción misteriosa del arte tiene mucho que ver con la armonía del derecho; a proporción pitagórica, la relación numérica del todo con las partes que aparece, por ejemplo, en un tema de Bach, con sus desarrollos y sus variaciones, la aparición del motivo y su lejana pero matemática y segura reaparición, tienen mucho que ver con el prodigio de forma del Código Napoleón, que Stendhal amaba (Couture, 1948).

Pero será en sus páginas sobre Abogados y Poetas en el Arte del Derecho donde finalmente desarrolla, con absoluta lucidez, esta relación:

Un escritor contemporáneo ha dicho que es más difícil encontrar poesía en el derecho que derecho en la poesía. Es ésta una verdad a medias [...] pero, en honor a la verdad, es necesario reconocer la exactitud de que hay mucho derecho en la poesía. [...].Hagamos una breve experiencia. Extraigamos de las páginas ilustres de la literatura universal, cuyos ejemplos se podrían renovar ilimitadamente, algunos de los más importantes casos; regocijémonos por un instante con la belleza de páginas inmortales, pero anotemos lo que ellas significan para la pobre ciencia del derecho. [...] Cierto escritor no carente de ingenio pudo enumerar hasta quince vicios de nulidad, de acuerdo con la ley mosaica en el proceso de 
Jesús. Sería de aconsejar que no se hiciera tanto en los procesos creados por los grandes genios de las bellas letras. Si así se hiciera, la humanidad habría perdido muchas de sus mejores páginas, y no pocas provechosas enseñanzas sobre la justicia, logradas a expensas de la ignorancia del derecho procesal (Couture, 2016, pp. 382-383).

Entre muchos de sus reconocimientos, fue designado miembro y vicepresidente de la Academia Nacional de Letras y condecorado con el Premio Nacional de Cultura. Ello despertó en él no solo estas reflexiones sino también su "necesidad espiritual de publicar un libro no jurídico", como forma de sentirse digno de tal titulación:

\footnotetext{
Me han conferido el Premio Nacional de Cultura. ¿Qué más? Todo esto me parece una usurpación, si no asumo, de una vez por todas, las responsabilidades que un escritor debe asumir. Es menester, pues, como Tartarín de Tarascón, salir al desierto a cazar leones. (Couture, 2016, p. 230).
}

Sus reflexiones, tan propias de su profunda visión de la condición humana y del derecho, dan cuenta de esa interrelación del Derecho en la literatura, que se desarrollaría en Latinoamérica, por lo menos, unas décadas después y que aún no es prácticamente considerada en la cultura jurídica uruguaya, como se referenció en el apartado anterior.

Sin lugar a duda, Couture fue un adelantado a su tiempo, siguiendo a Sarlo, por ejemplo, puede reconocerse el inicio de la interrelación entre Derecho y Literatura en la década del 60 con el movimiento Law and Literature de las escuelas críticas de derecho norteamericanas (Sarlo, 2013; Calvo González, 2018, pp. 1268-1278; Acedo Castilla, 1979, pp. 5-40).

En esta oportunidad, la Parábola de los cuatro príncipes nos permite disfrutar de ese Couture escritor literario - fusión entre el derecho y la literatura, la poesía, la estética-y sus concepciones sobre la justicia, la libertad, el orden, la tolerancia desde una mirada más estética, pero, no por ello, menos profunda.

\section{Parábola de los cuatro príncipes}

¿Es que, de los libros de Couture, solo son jurídicos los que consultamos
en los menesteres diarios de la profesión o de la investigación? (Sentís Melendo, 1957, p. 47).

Nuestra propuesta pretende advertir sobre la forma que este jurista encontró para relacionar dos de sus pasiones. También permite estudiar cómo su obra no jurídica 
redimensiona la justicia, complementando su aporte científico desde la ficción narrativa, en este caso particular, con la parábola; un género al que Couture le prestó singular atención

Inevitablemente las parábolas son asociadas al contenido religioso, sin perjuicio, con el paso del tiempo, pueden entenderse como una narración ficcional que pretende simplemente dar una enseñanza, poner en contexto un valor, una virtud.

Como explica Galves (a propósito de las parábolas de Jesús en el Nuevo Testamento), las parábolas son narrativas o relatos cuya anécdota es sencilla pero que plantea un problema de la realidad y compromete al lector o escucha. Por otro lado, le reconoce un valor pedagógico al abordar un tema de forma creíble, comprensible, verosímil (Galves Arcila, 2017, pp. 291-298).

Justamente Couture da este sentido a sus breves obras; al introducir una parábola en la obra Trayectoria y Destino del Derecho Procesal Hispanoamericano, en la que se cuestiona la condición humana, la vida y el honor en el sistema democrático expresamente explica: "Y como según el Evangelio todo se explica con parábolas, quisiera poner fin con una parábola que dijera lo más íntimo de mi sentimiento" (Couture, 1999, p. 315).

En otras palabras, Couture eligió conscientemente este "género", tomando como modelo las parábolas de Jesús, en las que reconoceremos algunas similitudes, por lo menos, macroestructurales y estilísticas.

Por su parte, la Parábola de los cuatro príncipes se encuentra agrupada con otras producciones literarias o, más precisamente, no jurídicas, en El arte del derecho y otras meditaciones (Couture de Landoni, 2016).

En Meditaciones sobre la libertad, aparece la Parábola del segador ciego, la que ensena brevemente sobre la profundidad de la libertad, su complejidad. Específicamente en El arte del derecho, Couture ofreció cuatro parábolas: Parábola de los filósofos, Parábola de la boda, Parábola del jardinero loco y, la que nos ocupa en esta instancia, Parábola de los cuatro príncipes.

La Parábola de la boda relata el discurso de un juez en una boda en que se resalta el valor de la ley y la seguridad jurídica. Por su parte, la Parábola de los filósofos, por medio de un diálogo entre filósofos al beber en la "fuente de la sabiduría", trata la problemática de la verdad, la filosofía y el derecho natural. La Parábola del 
jardinero loco ensena sobre los valores (justicia, caridad, verdad) por medio del diálogo entre un jardinero loco y sus flores.

En estos relatos podemos encontrar algunos rasgos literarios comunes entre sí y también con la parábola que nos ocupa, particularmente. En primer lugar, la anécdota como tal, es breve, simple, prácticamente irrelevante. ${ }^{2}$ Se presenta un diálogo sencillo entre dos o máximo tres personajes, entre los que es recurrente ya sea el juez o el filósofo; que será el personaje que da una respuesta o plantea la enseñanza.

En todos los casos, refiere a un cuestionamiento filosófico o a un valor, temática siempre presente en Couture, ya que su preocupación central no fue la ley o el derecho positivo, en que sólo ve un instrumento:

El Derecho es sólo un instrumento. Sin la justicia que lo ilumina, sin el orden que lo consolida, sin la educación que le da vida, sin la paz que lo impulsa, sin la equidad que lo tempera, sin la misericordia que lo suple, sin el amor que lo rebasa, sin el heroísmo que lo glorifica ¿qué es el Derecho? El homo juridicus, aquél que ajusta los actos de su vida a la rigurosa norma jurídica, es un prodigio de lógica y una caricatura del hombre (Couture, 1954; Delpiazzo, 2017, p.55).

La Parábola de los cuatro príncipes, como tal, puede ser interpretada en dos niveles, uno más "superficial", el análisis del relato, la anécdota en el sentido ya señalado. Y un nivel más "profundo", su proyección en un tema determinado, en este caso la justicia en relación con otros valores.

La anécdota, efectivamente, es sencilla, un rey confía el gobierno de cuatro comarcas a sus cuatro hijos y al cabo de un tiempo, luego de consultar a los súbditos cómo les ha ido, los reúne para aconsejarlos. Así, el relato se desarrolla en un contexto conocido, en términos de Bravo, como parte de "nuestra imaginería común", un rey que ofrece tierras a sus hijos príncipes para que las gobiernen, temática común en la literatura clásica española, por ejemplo. Ello hará que la parábola resulte comprensible y cercana a las estructuras del lector, en forma muy similar a lo que sucede en las

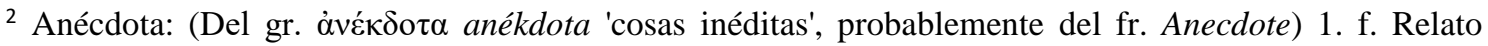
breve de un hecho curioso que se hace como ilustración, ejemplo o entretenimiento. 2. Suceso curioso y poco conocido que se relata en una anécdota. 3. Argumento de una obra 4. Suceso circunstancial o irrelevante (Real Academia Española, 1992).
} 
parábolas evangélicas de Jesús (Bravo, 2002, pp. 503-511 y Galvis Arcila, 2017, pp. 288-310).

Otro rasgo común, es la simplicidad en el lenguaje y de estructura estilística simétrica lo que también refuerza su carácter pedagógico.

Cada uno de ellos responde al rey cómo gobernará:

Tú gobernarás el Norte, dijo al primero. Gobernaré con justicia, respondió el hijo.

Tú gobernarás el Sur, dijo al segundo. Gobernaré con libertad, respondió el hijo.

Tú gobernarás el Este, dijo al tercero. Gobernaré con orden, respondió el hijo.

Tú gobernarás el Oeste, dijo al cuarto. Gobernaré con tolerancia, respondió el hijo.

Puede observarse una estructura simbólica en la que cada uno de los cuatro príncipes realiza una elección que luego dará diferentes resultados. Ello también se compadece con las parábolas de Jesús, por ejemplo, en la Parábola del Sembrador en la cual cada una de las cuatro semillas desplegará su fertilidad de acuerdo con dónde ha caído (Marcos 4 1-9. Sobre interpretación: Frías López et al., 2015, pp. 4-10).

En la elección de cada uno de estos príncipes aparecen: la justicia, la libertad, el orden y la tolerancia y, luego, en las palabras del rey, se manifiesta la compleja relación entre estos.

Este personaje central aparece como un rey dadivoso y justo, o más precisamente, equitativo, entrega a sus cuatro hijos iguales comarcas. Por otro lado, para conocer cómo les ha ido, no los consulta inicialmente a ellos, sino que escucha a los súbditos. Se trata de un rey, buen padre y que escucha a su pueblo. Ello resulta relevante ya que es la forma en que el narrador otorga legitimidad y autoridad a este rey que será la voz que dará lugar a la enseñanza o la reflexión.

Es, precisamente, en este diálogo entre el rey y sus súbditos que comienza el cuestionamiento sobre la realización de estos valores. La justicia puede tornarse dura y rigurosa; el exceso de libertad puede tornarse debilidad o libertinaje y el abuso del orden, tiranía. Veamos.

Los del Norte se quejaron del rigor de su príncipe. Es justo, dijeron, pero su justicia es muy dura. Comenzó por despojar a los ricos de sus riquezas, 
con lo cual los ricos le odiaron. Las dio a los pobres, pero muchos de éstos no supieron conservarlas, con lo cual se formó una nueva riqueza de los astutos. Ahora estudia la manera de despojar a los astutos. Vivimos litigando, los procesos se eternizan y los jueces no son infalibles. Para conquistar la justicia, hemos perdido la paz, y hoy no tenemos ni paz ni justicia.

El relato del súbdito de la comarca que sólo se gobierna por la justicia representa, además, una dura crítica a las debilidades del sistema; por un lado, la demora en la resolución de los problemas y, por otro, más dramático, los errores de los jueces.

Los del Sur se quejaron de la debilidad de su príncipe. Vivimos en libertad, pero la libertad ha degenerado en libertinaje, dijeron. Los comerciantes se enriquecen desmesuradamente; los industriales imponen a sus obreros condiciones inhumanas; los diarios no tienen freno alguno y los adversarios del gobierno conspiran amparados en nuestras libertades. El príncipe nada resuelve, pues considera que esa libertad es la felicidad del pueblo.

Los del Este se quejaron de la tiranía de su príncipe. Ha implantado, dijeron, un Estado policial. El orden impera en el reino, pero es un orden detectivesco; la policía ha entrado en el reducto de nuestros hogares, sigue cada uno de nuestros pasos y vive en acecho hasta de nuestros pensamientos. Ahora ha comenzado la delación, muchas veces los hijos delatan a los padres. El miedo se ha posesionado del reino.

El segundo y el tercer hijo también han tenido dificultades para gobernar; la libertad irrestricta genera debilidades y abusos y, por otro lado, el exceso del orden tiende a la tiranía. Esta visión se condice con la sabiduría de Su Santidad Juan XXIII en la encíclica Pacem in Terris, en la que ensena que la autoridad y el orden no se pueden apoyar exclusivamente en la amenaza o el temor. $\mathrm{Y}$ donde también resalta la importancia de la debida tutela de los derechos en equilibrio con la libertad

Los del Oeste se quejaron de la tolerancia de su príncipe. Pero no pudieron ponerse de acuerdo en lo que el reino necesitaba, pues unos pedían más justicia, otros más libertad y otros más orden. 
Ante estos dilemas, se introduce la voz del rey con la expresión Oído esto, que funciona pragmáticamente como introductor de la sentencia. Otra vez, el uso de un recurso similar al Evangelio El que tiene oídos para oír, oiga (Marcos 4, 1-9).

En ambos casos, oír es símbolo de entendimiento, escucha, apertura. El rey, dadivoso y justo, también es sabio, y comprendiendo a los súbditos de las cuatro comarcas impone su sentencia; elige a uno de sus hijos para gobernar todo el reino: su cuarto hijo quien había gobernado con tolerancia:

Pondrás en vigor los anhelos de justicia de tu hermano mayor, los de libertad del segundo y los de orden del tercero. Tu tolerancia te permitirá obtener todo aquello que tus hermanos no lograron. Ama la justicia, pero tolera ese poco de injusticia que los hombres por sí solos no pueden remediar; ama la libertad, pero tolera las necesarias restricciones a la libertad que aseguran la justicia y el orden; y ama el orden, pero tolera ese poco de desorden necesario para asegurar a nuestro pueblo los beneficios de la justicia y de la libertad.

He aquí la enseñanza, las virtudes se realizan en forma conjunta, es necesario, su delicado equilibrio para lograr la paz o convivencia pacífica. El rey se inclina por uno de sus hijos como sucesor, el cuarto, el menor, quien ha elegido para gobernar, primeramente, con tolerancia.

En esta elección queda de manifiesto que la ley puede quebrantarse si no se cumple con su finalidad última; la justicia. El rey no elige al hijo mayor, por la línea monárquica sucesoria como impone la ley. Por el contrario, elige al menor, al más joven quien representa la tolerancia. La concibe como aquella que permite realizar los otros valores, imprescindibles.

La libertad debe protegerse, el orden es necesario, pero todos ellas requieren de la tolerancia para aceptar los errores en el ejercicio de la justicia, para comprender las ineludibles restricciones a la libertad y para permitir aquellas acciones fuera del orden pero que garanticen la libertad y la integridad.

El monarca armoniza los valores, no hace prevalecer uno sobre otro, y esa es la riqueza. La tolerancia es el sostén de la justicia, la libertad y el orden.

La necesidad de reivindicar la tolerancia como valor es producto de la modernidad y de la fragilidad de estos tiempos; como lo fue la época de postguerra, en 
que se crea esta parábola. Cuando la sociedad se ve quebrantada ya sea producto de una guerra o fragmentada ideológicamente, o socialmente debilitada, la tolerancia parece ser una legítima alternativa de pacificación.

Como analiza Téllez, sin embargo, en la Edad Media ya la tolerancia aparece incorporada a la conciencia colectiva (Téllez Maqueo, 2008, p. 164). También Solari advierte que, si bien la tolerancia parece identificarse con los tiempos modernos, una mirada más atenta permite contestar dicha afirmación, lo que se constata con Santo Tomás de Aquino. En la Summa Theologiae, el Aquinate refiere a la tolerancia hacia los ritos de los judíos y hacia los herejes (S.T.II-II, q.10. a.11 y II-II, q.11, a.3).

Así, en el medioevo, la tolerancia no exige relegar la verdad sino, por el contrario, reconocer la limitación humana en ese camino a alcanzarla. Es entendida como la posibilidad de no intervenir, de permitir aquello que no se aprueba, pero no abandonar la verdad (Solari, 2013, pp. 76-91).

Pero el rey, en esta narración, a su vez, relaciona la tolerancia a la justicia, la libertad y el orden. Lo que finalmente el autor, en la voz del rey, quiere trasmitir, es que no hay justicia, libertad ni orden sin tolerancia, esta última permite realizar aquellas.

Esa es tal vez la gran riqueza de este texto, nos muestra, de la mano de un rey valiente, un camino para alcanzar el fin último, que altera la ley sucesoria establecida para hacer prevalecer la tolerancia como instrumento para la justicia, en armonía con otros valores, íntimamente relacionados, al extremo que el rey otorga todo el poder a quien gobierna con la primera, que sólo así permitirá alcanzar la justicia, pero no por ello deben confundirse.

De hecho, este sincretismo de Couture responde, probablemente, al hombre humanista de la primera mitad del SXX que vivió los horrores de la guerra, fiel e íntimo amigo de Goldschmidt Precisamente en oportunidad de un discurso en su homenaje, explica lo que ha denominado la "ley de la tolerancia":

¿Cuál es la ley que sirve al mismo tiempo para el banquero, para el artista y para el mártir? ¿Cuál es el principio de convivencia humana que sirve para los tres, que ven la vida de tan opuesta manera? Este es el secreto de todo el arte de gobernar. Si pudiéramos tener tres leyes, una para cada uno de esos distintos hombres, acaso la vida fuera menos difícil. Pero necesitamos algo que los comprenda a todos. [...] La ley de la tolerancia significa, ante todo, comprender a nuestro semejante. Nunca tendremos en 
la mano toda la verdad; ésta debe ser nuestra única certeza. Debemos ser conscientes de que siempre caerá de entre nuestras manos, como si las tuviéramos llenas de arena, una cantidad de granos que se escurrirán de entre los dedos y que irán a parar a manos de nuestros adversarios. Debemos saber que no es ningún mérito respetar las ideas que compartimos sino que el mérito consiste en respetar las ideas que aborrecemos. (Couture, 1955; Landoni Sosa, 2017, pp. 23-30).

Estas enseñanzas por medio del inagotable género que es la parábola, otorgan una continua posibilidad de relecturas. El problema de los valores adquiere especial relevancia en la sociedad actual, caracterizada por una "ataraxia valorativa", surgiendo, entonces, el desafío de darle una oportunidad a los valores. Desde esta visión, Portela coincide al concebir a la justicia como "fin" y al analizar la relación entre justicia, orden moral y orden jurídico advierte que la justicia se goza en la paz y la seguridad (Portela, 2016, p. 19).

También, desde una perspectiva más confesional, Ocáriz advierte que la tolerancia no es ilimitada, ni es sinónimo de indiferencia ni desapego a la verdad, pero sí necesaria para el bien común, no es un fin en sí mismo como la justicia (Ocáriz, 1995, pp. 882-883). Por su parte, Su Santidad Juan Pablo II en su mensaje para la celebración de la XXIV Jornada Mundial de la Paz, en 1991, encuentra en la intolerancia una amenaza para la paz.

La tolerancia es la posibilidad de alcanzar la verdad y la justicia. Permitirnos las diferencias, reconociendo nuestras limitaciones humanas, será parte del camino hacia la verdad. Tolerar no es eludir la verdad, a la que tendemos naturalmente, sino, por el contrario, aceptar el proceso para aprehenderla y lograr el orden justo. Tampoco tolerar es consentir lo injustificable sin límite alguno, no se trata de tolerar indefinidamente el mal, sino vencer con el bien el mal (Romanos, 12, 21).

\section{Conclusiones y reflexión final}

La lectura del arte del derecho (...) que trasunta un profundo amor al prójimo y un sentimiento tutelar o protector de los derechos humanos, especialmente los de los más débiles, seduce y atrapa, y define a un ser humano de virtudes excepcionales (Van Rompaey, 2016, XXVIII). 
Sin dudas el derecho — de la mano de la literatura - se vuelve más vivencial, liberador. Por otro lado, la literatura, como explica Roggero, al centrarse en lo singular, a lo evanescente, lo contingente - de la mano del derecho- trasciende la historia individual hacia una vocación más universal (Roggero, 2017, pp. 145-146).

Pocos como Couture han dado cuenta del sincretismo entre la formalidad del análisis del derecho positivo, la trascendencia del Derecho y la belleza creativa de la ficción literaria; entre el "todo vale" de la literatura y el "el tener que" del Derecho (Ost, 2006, pp. 336-337).

Con su producción literaria nos invita a acercarnos al derecho en un recorrido entre lo real y la fantasía y, así, a través del discurso parabólico, nos sumerge, con habilidad y lucidez, en su pensamiento filosófico más profundo. Particularmente en la Parábola de los cuatro príncipes da cuenta de la compleja y frágil relación entre la justicia, libertad, orden y tolerancia.

De nuestra parte, con el humilde propósito que colaborar en la reflexión, nos atrevemos a compartir el pensamiento de Téllez sobre el alcance de la tolerancia en la verdad:

Aún hoy habría que preguntarse si la tolerancia que se practica es sólo un velo elegante tras del cual se oculta cierto indiferentismo ante la búsqueda de la verdad. Así, pues, la vida erística, con todos los inconvenientes y efectos que genera la disputa, pertenece a la naturaleza misma del quehacer filosófico. No hace falta defender la propia fe en el circo romano para ser un mártir en el terreno intelectual: el filósofo que defiende -con pasión o con serenidad, de cualquiera de las dos formas- sus creencias con la fuerza de los argumentos en medio de sus detractores, está practicando otro tipo de «martirio» y bajo el influjo de otra clase de «fuego» más discreto, más elegante, pero no menos corrosivo y deletéreo (Téllez Maqueo, 2008, p. 172)

Deseamos que este breve análisis haya evocado otra cara del destacado jurista Couture, y como él mismo describió a Juana de Ibarbourou (Couture, 2016, p. 278), el hombre es uno y varios a la vez y su mejor versión es la síntesis de todas ellas. 


\section{Nota}

Este trabajo se realizó en el marco del Proyecto de Investigación "Principales problemas de justicia y su solución en la literatura universal", dirigido por el Dr. Siro M.A. De Martini. Programa Ius - Acreditación de Proyectos de Investigación Jurídica. Investigación jurídica aplicada. Facultad de Derecho. UCA. Convocatoria 2019-2021.

\section{Referencias}

Acedo Castilla, J. (1979). El rey, la justicia y el derecho en nuestra literatura de la Edad de Oro. Boletín de la Real Academia Sevillana de Buenas Letras, 7, 5-40.

Bauman, Z. (2002). Modernidad líquida. Buenos Aires, Argentina: Fondo de Cultura Económica.

Bravo, L. (2002). La pedagogía de las parábolas. Una perspectiva psicológica. Teología y Vida, 43(4), 503-511.

Buonocore, D. (1957). Eduardo J. Couture [disertación pronunciada en el acto de homenaje que tuvo lugar en el aula Alberdi de la Facultad de Ciencias Jurídicas y Sociales de la Universidad Nacional del Litoral el 9 de noviembre de 1956]. Universidad, (34), 101107.

Calvo González, J. (2018). Práctica jurídica y cultura literaria del derecho. Revista Eletrônica do Curso de Direito da UFSM, 13(3), 1268-1278. Recuperado de https://periodicos.ufsm.br/revistadireito/article/view/35881

Cárcova, C. M. (2000). Derecho, literatura y conocimiento. Revista Jurídica de Buenos Aires, 198. Recuperado de http://www.saij.gob.ar/carlos-maria-carcova-derecho-literaturaconocimiento-dacf010072-2000/123456789-0abc-defg2700-10fcanirtcod\#

Couture, E. J. (11 de junio de 1948). Semblanza a Irureta Goyena. Conferencia en la Academia Nacional de Letras, Montevideo, Uruguay.

Couture, E.J. (15 de marzo de 1954). Discurso Inaugural de la VII Conferencia Interamericana de Abogados. San Pablo.

Couture, E. J. (1955). La libertad y la cultura. James Goldschmidt: un judio muerto por la libertad de la cultura. Conferencia en Instituti Ulpan, Montevideo, Uruguay.

Couture, E. J. (1956). Tres poetas del derecho: Bentham, Valéry, Rodó. [Conferencia pronunciada en el salón de actos de la Biblioteca Popular de Paraná el 3 de abril de 1956]. Universidad, (32), 99-121.

Couture, E. J. (1999). Trayectoria y destino del derecho procesal hispanoamericano. Buenos Aires, Argentina: Depalma.

Couture, E. J. (2016). Obras completas. Tomos I-VI. Montevideo, Uruguay: La Ley. 
Couture de Landoni, I. (2016), Los mandamentos del Abogado. El arte del Derecho y otras meditaciones. Montevideo, Uruguay: La Ley.

Delpiazzo, C. E. (2017). Incidencia del pensamiento de Eduardo J. Couture en la formación de los profesionales del derecho. En Á. Landoni Sosa y S. Pereira Campos, Estudios de Derecho Procesal en homenaje a Eduardo J. Couture (I, 53-65). Montevideo, La Ley.

Frías López, A. K., Baños Everardo, M. C., Carrera Ruiz, R., López Martínez, R., y Arenas Martínez, S. R. (2015). El plano semántico de la "Parábola del sembrador", de acuerdo con el conflicto de las interpretaciones de Paul Ricoeur. Cínzontle, 7(15), 4-10.

Galvis Arcila, S. (2017) La reflexión pedagógica a partir de las parábolas de Jesús. Una apuesta investigativa. Cuadernos de Teología, IX (2), 288-310.

Hinojosa, E. d. (1904). Discurso de recepción a la Real Academia Española. En Discursos leídos ante S. M. Rey Don Alfonso XIII presidiendo la Real Academia Española en la recepción pública del Exmo. Sr. Don Eduardo de Hinojosa el 6 de marzo de 1904 (pp. 5-41). Madrid, España: Imprenta del Asilo de Huérfanos del Sagrado Corazón de Jesús.

Landoni Sosa, Á. (2017). "Semblanza de Eduardo J. Couture”. En Á. Landoni Sosa y S. Pereira Campos. Estudios de Derecho Procesal en homenaje a Eduardo J. Couture (tomo I, 2330). Montevideo. La Ley.

Lorca, M. I. (2012). Derecho y literatura: género, libertad y justicia en la obra dramática de García Lorca. Revista Prolegómenos. Derechos y Valores, 15(30), 119-140.

Marí, E. (1998). Derecho y literatura. Algo de lo que sí se puede hablar pero en voz baja. DOXA. Cuadernos de Filosofía del Derecho, 2(21), 251-287.

Martínez Segovia, F. (1956). Presentación de la conferencia magistral de Couture en el salón de actos de la Biblioteca Popular de Paraná. Universidad, 32, 99-121.

Meliante Garcé, L. y Sosa, M. J. (2018). Derecho y literatura. Interdisciplinariedad, cruces inevitables y réditos posibles. Cuadernos del CLAEH, 37(108), 59-82.

Ocáriz, F. (1995). Delimitación del concepto de tolerancia y su relación con el principio de libertad religiosa. Scripta Theologica, 27(3), 865-883.

Ost, F. (2006). El reflejo del derecho en la literatura. DOXA. Cuadernos de Filosofía del Derecho, 29, 333-348.

Portela, J. G. (2016). La Justicia y el Derecho natural. Buenos Aires, Argentina:EDUCA.

Roggero, J. (2017). ¿Cómo no hablar de "Derecho y Literatura"? Cinco tesis. Revista Jurídica de la Universidad de Palermo, 15(1), 144-147.

Sarlo, Ó. (2013). Testimonio de una vocación intelectual [discurso de ingreso a la Academia Nacional de Letras de Uruguay]. Recuperado de http://www.academiadeletras.gub.uy/

Sentís Melendo, S. (1957). Couture y su obra procesal (25 años de labor). Derecho PUCP. Revista de la Facultad de Derecho, 16, 43-70.

Solari, E. (2013). Contornos de la tolerancia medieval. Ideas y Valores, 62(153), 73-97. 
Téllez Maqueo, D. (2008). La tolerancia en santo Tomás de Aquino. Espíritu: cuadernos del Instituto Filosófico de Balmesiana, 137, 161-172.

Van Rompaey, L. (2016). Couture, Eduardo J Obras Completas. Tomo I. Montevideo, Uruguay: La Ley.

\section{Contribución autoral}

a) Concepción y diseño del trabajo; b) Adquisición de datos; c) Análisis e interpretación de datos; d) Redacción del manuscrito; e) revisión crítica del manuscrito.

M. C. B. C. ha contribuido en a, b, c, d, e.

Editor científico responsable: Dra. María Paula Garat. 